\title{
Neurotrophin-Regulated Sorting of Opioid Receptors in the Biosynthetic Pathway of Neurosecretory Cells
}

\author{
Kyung-Ah Kim and Mark von Zastrow \\ Departments of Psychiatry and Cellular and Molecular Pharmacology, University of California, San Francisco School of Medicine, San Francisco, California \\ 94143-0984
}

Neurotrophins modulate the endogenous opioid system, but the underlying mechanisms are poorly understood. We observed an unexpected effect of neurotrophin signaling on the membrane trafficking of recombinant opioid receptors expressed in neurosecretory cells. Epitope-tagged $\delta$ opioid receptor (DOR) and $\mu$ opioid receptor (MOR) were differentially localized between surface and internal membrane pools, respectively, when expressed in primary cultured hippocampal neurons, consistent with previous studies by others of natively expressing neurons. Selective intracellular targeting of DOR was observed in nerve growth factor (NGF)-differentiated PC12 neurosecretory cells but not in PC12 cells cultured in the absence of NGF, where both DOR and MOR were localized in the plasma membrane. Surprisingly, NGF initiated intracellular targeting of DOR in PC12 cells acutely, within $60 \mathrm{~min}$ after initial activation of TrkA. The NGF-induced intracellular pool of DOR originated from a late stage of the biosynthetic pathway after exit from the endoplasmic reticulum and processing of $\mathrm{N}$-linked glycans in the Golgi, resulting in the accumulation in cells of a biochemically mature "reserve" pool of intracellular DOR that exhibited depolarization-dependent insertion into the plasma membrane. The C-terminal cytoplasmic tail of DOR contains a signal determining the specificity of NGF-regulated intracellular targeting. These results indicate that cloned opioid receptors are differentially targeted when expressed heterologously in neurosecretory cells, establish a model system that facilitates mechanistic study of this process, and suggest a novel function of neurotrophins in modulating the anterograde membrane trafficking of opioid receptors.

Key words: opioid; membrane trafficking; regulation; neurotrophin; exocytosis; plasticity

\section{Introduction}

A fundamental means by which neurons regulate signal transduction is by modulating the number of specific receptors present in their plasma membrane (Carroll et al., 2001; Sheng and Lee, 2001; Tsao and von Zastrow, 2001). The removal of neural signaling receptors from the plasma membrane by regulated endocytosis has been studied in considerable detail (Keith et al., 1998; Whistler et al., 1999; Man et al., 2000; Sheng and Lee, 2001). The converse process, regulated insertion of receptors into the plasma membrane, plays an important role in modulating the functional activity of certain signaling receptors (Zhang et al., 1998; Shi et al., 1999; Shuster et al., 1999; Sheng and Lee, 2001) but is less well understood.

Opioid receptors comprise a subfamily of structurally homologous G-protein-coupled receptors (GPCRs) that mediate the effects of endogenously produced opioid neuropeptides and exogenously administered opiate analgesic drugs. In non-neural cells, both $\mu$ opioid receptor (MOR) and $\delta$ opioid receptor (DOR) are targeted to the plasma membrane and remain at the cell surface unless removed by ligand-induced endocytosis (Keith et al., 1996; Trapaidze et al., 1996). A similar membrane-

\footnotetext{
Received Sept. 5, 2002; revised Dec. 3, 2002; accepted Dec. 30, 2002.

This work was supported by National Institutes of Health (NIH) Grants DA 10154 and DA 00439 (M.v.). K.-A. K. was supported by NIH Institutional Training Grant MH 19552. We thank Dr. Allan Basbaum, Steinunn Baekkeskov, Dr. Eric Beattie, Dr. Moses Chao, Dr. Robert Edwards, Dr. Doris Fortin, Dr. Nadine Jarousse, Dr. Jamil Kanaani, Dr. Regis Kelly, Dr. Francis Lee, Dr. Robert Malenka, and Dr. Adena Svingos for reagents and valuable discussion.

Correspondence should be addressed to Mark von Zastrow, University of California, San Francisco, 401 Parnassus Avenue, Box 0984F, Room LP-A104, San Francisco, CA 94143-0984. E-mail: zastrow@itsa.ucsf.edu. Copyright $\odot 2003$ Society for Neuroscience $\quad 0270-6474 / 03 / 232075-11 \$ 15.00 / 0$
}

trafficking itinerary appears to apply to MOR endogenously expressed in neural cell types (Sternini et al., 1996; Keith et al., 1998; Ko et al., 1999; Cahill et al., 2001; He et al., 2002). However, there are profound differences in the subcellular targeting of DOR in native neurons compared with heterologous cell types. Endogenously expressed DORs are localized at a steady state predominantly in intracellular membranes of neurons in brain and spinal cord, even in the absence of ligand-induced activation (Svingos et al., 1995; Cheng et al., 1997; Zhang et al., 1998). Furthermore, DORs are observed in intracellular vesicles of the same neurons in which endogenously coexpressed MORs are present at the cell surface, suggesting that intracellular targeting of opioid receptors results from a specific membrane sorting event (Wang and Pickel, 2001). Moreover, in some cases, intracellular opioid receptors are translocated to the neuronal plasma membrane in response to physiological or pharmacological stimuli, and this process is thought to play a critical role in potentiating the responsiveness of specific neurons to opioid agonists (Zhang et al., 1998; Shuster et al., 1999; Cahill et al., 2001).

We have investigated the targeting of recombinant opioid receptors expressed in cultured neurons and neurosecretory cells. Here we show that cloned DOR, like its native counterpart, is preferentially targeted to intracellular membranes, whereas cloned MOR is predominantly targeted to the plasma membrane. Our studies identify the existence of a regulated mechanism by which DOR is selectively targeted from the late biosynthetic pathway to a distinct intracellular membrane pool that can be inserted into the plasma membrane in response to depolarization. 


\section{Materials and Methods}

\section{cDNA constructs}

FLAG (DYKDDDD) and hemagglutinin (HA) epitope-tagged versions of the cloned murine $\delta$ (DOR1; Evans et al., 1992) and $\mu$ (MOR1) (Kaufman et al., 1995) opioid receptors were cloned into pcDNA3 (Invitrogen, San Diego, CA) as described previously (Keith et al., 1996; Gage et al., 2001). A CD4-DOR tail was constructed by inserting a PCR product encoding the DOR tail (amplified from pcDNA3-DOR by PCR using the $5^{\prime}$ upstream sense primer 5'-GAACAGGATATCGACGAGAACTTCAAGCGC-3' and the $3^{\prime}$ primer $5^{\prime}$-TAGAAGGCACAGTCGAGG-3'), which was digested with EcoRV and XhoI and ligated into SmaI and XhoI sites present in the cytoplasmic tail of a construct encoding CD4 cloned into pCR3.1 [provided by Dr. Nadine Jarousse and Dr. Regis Kelly, University of California San Francisco (UCSF)]. A chimeric mutant opioid receptor, in which the cytoplasmic tail of MOR was replaced with the corresponding sequence from DOR, was described previously (Whistler et al., 1999). All mutated sequences were confirmed by dideoxynucleotide sequencing (UCSF Genetics Core Facility).

\section{Cell culture and transfection}

Rat pheochromocytoma (PC12) cells (provided by Dr. Robert Edwards, UCSF) were grown in DMEM (UCSF Cell Culture Facility) supplemented with $10 \%$ cosmic calf serum (Hyclone, Logan, UT) and 5\% equine serum (Hyclone). TrkA-deficient PC12 cells (clone nnr5; provided by Dr. Francis Lee and Dr. Moses Chao, Weill Medical College of Cornell University, Ithaca, NY) were grown in RPMI 1640 medium (UCSF Cell Culture Facility) supplemented with 10\% fetal bovine serum (Hyclone) and 5\% equine serum (UCSF Cell Culture Facility). Human embryonic kidney 293 cells (American Type Culture Collection, Manassas, VA) were grown in DMEM supplemented with $10 \%$ fetal bovine serum. Cells were plated at $\sim 60 \%$ confluency the day before transfection. PC12 cells were transfected by electroporation in a $0.4 \mathrm{~cm}$ cuvette at 0.3 $\mathrm{kV}$ and $960 \mu \mathrm{F}$ using a Gene Pulser (Bio-Rad, Hercules, CA) in electroporation medium (RPMI 1640 medium, 10\% cosmic calf serum, $10 \mathrm{~mm}$ dextrose, and $0.1 \mathrm{~mm}$ DTT). PC12 nnr5 cells and human embryonic kidney 293 (HEK293 cells) were transfected using Effectene (Qiagen, Hilden, Germany) according to the manufacturer's instructions. Clones of stably transfected cells were selected using either $250 \mu \mathrm{g} / \mathrm{ml}$ Geneticin (Invitrogen) or $100 \mu \mathrm{g} / \mathrm{ml}$ Zeocin (Invitrogen). Hippocampal neuron cultures were prepared from postnatal day 0 rats as described previously (Carroll et al., 1999; Lissin et al., 1999) and plated on poly-D-lysinecoated coverslips, and 5- to 7-d-old cultures were transfected using Effectene. Experiments were conducted on transiently transfected cells $48-72 \mathrm{hr}$ after transfection.

\section{Immunocytochemical staining}

For immunocytochemical localization of opioid receptors, cells grown on poly-D-lysine-coated glass coverslips were fixed in $4 \%$ formaldehyde in PBS, washed with Tris-buffered saline, and permeabilized using $0.1 \%$ (v/v) Triton X-100 (Sigma, St. Louis, MO) in blocking solution (4\% dry milk, $25 \mathrm{~mm}$ Tris, $137 \mathrm{~mm} \mathrm{NaCl}, 3 \mathrm{~mm} \mathrm{KCl}$, and $1 \mathrm{mM} \mathrm{CaCl}_{2}$ ). Indirect immunofluorescence staining of HA- and FLAG-tagged receptors was performed using murine HA.11 anti-HA antibody $(5 \mu \mathrm{g} / \mathrm{ml}$; Babco, Berkeley, CA) and murine M1 anti-FLAG antibody ( $4.2 \mu \mathrm{g} / \mathrm{ml}$; Sigma), respectively, and then using fluorochrome-labeled secondary antibodies (Jackson ImmunoResearch, West Grove, PA) as described previously (Keith et al., 1996). To specifically visualize internalization of DOR from the cell surface, an "antibody-feeding" experiment was conducted as described previously (Keith et al., 1996). Briefly, HA.11 anti-HA antibody $(5 \mu \mathrm{g} / \mathrm{ml})$ was added to the culture medium of stably transfected PC12 cells expressing HA-tagged DOR, and then the cells were further incubated in the presence of $10 \mu \mathrm{M}$ 2-D-Ala, 3-D-Leu enkephalin (DADLE; Research Biochemicals, Natick, MA) or $100 \mathrm{ng} / \mathrm{ml}$ nerve growth factor (NGF; Roche Molecular Biochemicals, Indianapolis, IN) for 30 or $60 \mathrm{~min}$, respectively. Cells were then fixed using formaldehyde, and endocytosed antibody was detected by incubating permeabilized cells with Cy3 donkey anti-mouse antibody ( $1.5 \mu \mathrm{g} / \mathrm{ml}$; Jackson ImmunoResearch). Dual localization of HA-tagged DOR and trans-Golgi network 38 (TGN38) in the same cells was performed by first incubating permeabilized cells with anti-HA HA.11 mouse antibody and antiTGN38 rabbit antibody (a gift from Dr. Robert Edwards) and washed in Tris-buffered saline. Bound HA.11 and anti-TGN38 antibodies were visualized using fluorescein isothiocyanate (FITC)-conjugated goat antimouse antibody (Jackson ImmunoResearch) and Texas Red-conjugated goat anti rabbit antibody (Jackson ImmunoResearch), respectively. Stained specimens were examined by epifluorescence microscopy using a Nikon (Melville, NY) Diaphot microscope equipped with a $60 \times$ numerical aperture (NA) 1.4 objective, mercury arc lamp illumination, and standard dichroic filter sets (Omega Optical). Images were collected using a cooled charge-coupled camera (Princeton Instruments) interfaced to an Apple (Cupertino, CA) Macintosh computer. Laser-scanning confocal fluorescence microscopy was performed using a Bio-Rad MRC 1000 instrument equipped a with Zeiss (Thornwood, NY) $100 \times$ NA1.3 objective or a Zeiss LSM 510 microscope equipped with a $63 \times$ NA1.3 objective. For quantification of images, coverslips were coded and examined in a blinded manner by epifluorescence microscopy. Cells were scored according to whether they contained a prominent intracellular pool of receptor immunoreactivity. Cells possessing $>30$ perinuclear vesicles exhibiting receptor staining intensity greater than or equal to that present in the plasma membrane were scored as "intracellular." Approximately 100 cells were selected at random and analyzed for each condition in each experiment. The results of three to five independent experiments were compiled for each experiment. Bars in the figures represent mean values calculated from the compiled experiments, and error bars represent the SEM between these independent experiments.

\section{Biochemical assays of receptor internalization}

Surface biotinylation. To measure internalization of DOR biochemically, a minor modification of a previously described biotinylation assay (Cao et al., 1999; Whistler et al., 1999) was used. Cells grown to $80 \%$ confluence in poly-D-lysine-coated $100 \mathrm{~mm}$ dishes were incubated with 30 $\mu \mathrm{g} / \mathrm{ml}$ sulfo- $N$-hydroxysuccinimide (NHS)-SS (dithio)-biotin in PBS at $4^{\circ} \mathrm{C}$ for $30 \mathrm{~min}$ to biotinylate surface receptors. Unreacted biotinylation reagent was inactivated by incubating cells with Tris-buffered saline. Cells were then returned to the $37^{\circ} \mathrm{C}$ incubator in normal culture medium and treated with $100 \mathrm{ng} / \mathrm{ml} \mathrm{NGF}$ ( $1 \mathrm{hr}$ ) or $10 \mu \mathrm{M}$ DADLE (30 min). After treatment, the remaining surface biotin was cleaved by incubating cells in glutathione reducing buffer ( $50 \mathrm{~mm}$ glutathione, $75 \mathrm{~mm} \mathrm{NaCl}, 75$ $\mathrm{mm} \mathrm{NaOH}$, and $10 \% \mathrm{FBS}$ ) followed by quenching of unreacted glutathione using iodoacetamide buffer $(0.9 \%$ iodoacetamide and $1 \%$ BSA in PBS). The cells were then immediately lysed in cold lysis buffer $(0.1 \%$ Triton X-100, $10 \mathrm{~mm}$ Tris, $150 \mathrm{~mm} \mathrm{NaCl}, 1 \mathrm{~mm} \mathrm{CaCl}_{2}$, and $25 \mathrm{~mm} \mathrm{KCl}$ ) containing protease inhibitors ( $100 \mu \mathrm{g} / \mathrm{ml}$ leupeptin, aprotinin, and pepstatin and $1 \mathrm{~mm}$ pefabloc). The remaining internalized biotinylated receptors were isolated by binding to streptavidin-agarose beads (Pierce, Rockford, IL), resolved by SDS-PAGE, and detected by immunoblotting using anti-HA HA.11 antibody.

Fluorescence flow cytometry. Internalization of epitope-tagged receptors was estimated by a previously described method (Keith et al., 1996) for detecting the immunoreactivity of surface receptors by flow cytometry. Briefly, monolayers of cells stably expressing HA epitope-tagged DOR were incubated in the presence of $100 \mathrm{ng} / \mathrm{ml} \mathrm{NGF}$ for $1 \mathrm{hr}$ at $37^{\circ} \mathrm{C}$ and then chilled on ice to stop membrane trafficking. Cells were lifted in EDTA containing PBS, washed twice with PBS at $4^{\circ} \mathrm{C}$, and then incubated with HA11 anti-HA antibody $(2.5 \mu \mathrm{g} / \mathrm{ml})$ in PBS for $1 \mathrm{hr}$. After washing, cells were further incubated with FITC-conjugated goat anti-mouse antibody for $30 \mathrm{~min}$ followed by washing. Receptor immunoreactivity was quantified by fluorescence flow cytometry (FACScan; Becton Dickinson, Mountain View, CA). The fluorescence intensity of 10,000 cells was collected, and Cellquest software (Becton Dickinson) was used to calculate mean fluorescence intensities from each distribution. Receptor internalization was calculated by determining the reduction of surface fluorescence staining intensity relative to that of control (untreated) cells (Keith et al., 1996).

\section{Metabolic labeling, immunoprecipitation, and biochemical} analysis of receptor glycosylation

Stably transfected PC12 cells expressing HA- or FLAG-tagged opioid receptors were grown on $100 \mathrm{~mm}$ dishes and preincubated with $3 \mathrm{ml}$ of 


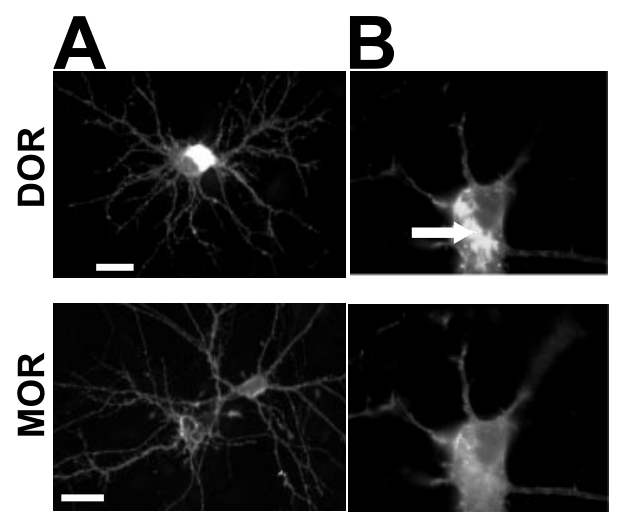

Hippocampal neurons

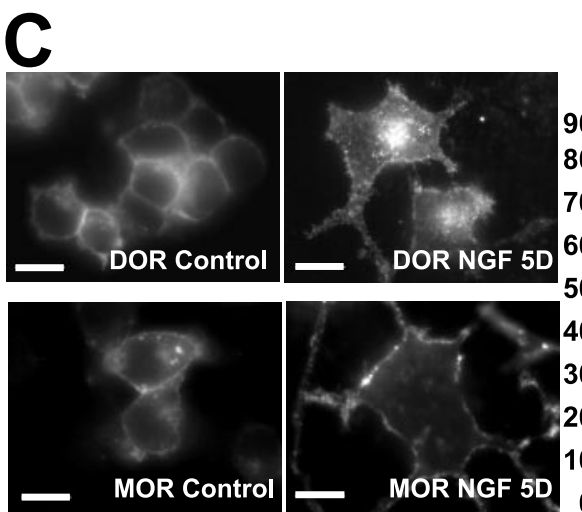

PC 12 cells

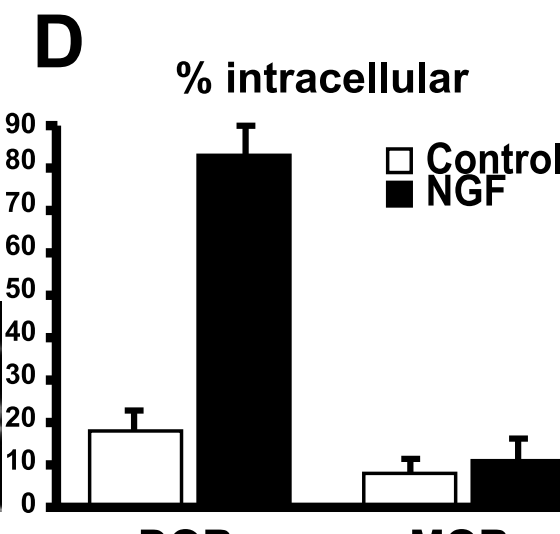

DOR

MOR

Figure 1. Subtype-specific targeting of opioid receptors in transfected hippocampal neurons and PC12 neurosecretory cells. A, Hippocampal neurons in primary culture were transfected with FLAG-tagged DOR or MOR. Cells were fixed $3 \mathrm{~d}$ after transfection and permeabilized, and the subcellular distribution of receptors was visualized by indirect immunofluorescence microscopy. Representative epifluorescence images are shown. Scale bars, $20 \mu \mathrm{m}$. B, Higher-magnification view of a cultured hippocampal neuron cotransfected with plasmids encoding FLAG-tagged DOR and HA-tagged MOR after fixation and dual localization of receptors. Scale bar, $10 \mu \mathrm{m}$. C, Stably transfected PC12 cells expressing epitope-tagged DOR or MOR were incubated with $50 \mathrm{ng} / \mathrm{ml}$ NGF for $5 \mathrm{~d}$ to promote morphological differentiation and then fixed and processed for immunofluorescence microscopy. Representative micrographs of untreated control and NGF-differentiated cells are shown. Scale bars, $10 \mu \mathrm{m}$. D, Quantitative analysis of the results illustrated in C, conducted by scoring $\sim 100$ cells for each condition in each experiment. The proportion of cells in which receptors were localized predominantly in intracellular membranes (determined in blinded samples as described in Materials and Methods) is presented as mean \pm SEM determined from analysis of three independent experiments.

Cys- and Met-free DMEM (UCSF Cell Culture Facility) containing 10\% dialyzed FBS for $2 \mathrm{hr}$ before the incubation with $100 \mathrm{ng} / \mathrm{ml} \mathrm{NGF}$. After preincubation of cells in the presence or absence of NGF for $30 \mathrm{~min}, 0.4$ $\mathrm{mCi} / \mathrm{ml}\left[{ }^{35} \mathrm{~S}\right]$ Express protein-labeling mix (PerkinElmer Life Sciences, Emeryville, CA) was added to the medium, and cells were subsequently incubated for the indicated times. Cells were washed in ice-cold PBS twice and lysed in lysis buffer $(0.1 \%$ Triton X-100, $10 \mathrm{~mm}$ Tris, $150 \mathrm{~mm}$ $\mathrm{NaCl}, 1 \mathrm{mM} \mathrm{CaCl}_{2}$, and $25 \mathrm{~mm} \mathrm{KCl}$ ) containing protease inhibitors (100 $\mu \mathrm{g} / \mathrm{ml}$ leupeptin, aprotinin, and pepstatin and $1 \mathrm{~mm}$ pefabloc). HA- or FLAG-tagged receptors were immunoprecipitated from cell extracts using HA.11 anti-HA antibody, $(5 \mu \mathrm{g} / \mathrm{ml}$; Babco $)$ or M1 anti FLAG antibody ( $4.2 \mu \mathrm{g} / \mathrm{ml}$; Sigma), respectively, and resolved by SDS-PAGE under nonreducing conditions. Proteins were fixed, and gels were soaked in Amplify (Amersham Biosciences, Arlington Heights, IL) and dried under vacuum at $60-80^{\circ} \mathrm{C}$. Fluorography was performed by exposing to $\mathrm{X}$-Omat film (Amersham Biosciences), and autoradiography was performed using a Storm PhosphorImager (Molecular Dynamics, Sunnyvale, CA). N-linked glycosylation of opioid receptors was analyzed by digestion with endoglycosidase $\mathrm{H}$ and endoglycosidase $\mathrm{F}$ (New England Biolabs, Beverly, MA) according to the manufacturer's instructions, with minor modifications as specified in the legend to Figure 4.

Biochemical assay of receptor insertion into the plasma membrane To examine whether the intracellular pool of DOR could undergo stimulus-dependent insertion to the plasma membrane, preexisting surface receptors were chemically "masked" by reacting them for $30 \mathrm{~min}$ at room temperature with sulfo-NHS 7-amino 4 methyl coumarin-3-acetic acid (AMCA; Pierce). This is a membrane-impermeant reagent (verified by fluorescence microscopy) that irreversibly modifies the same amine moieties as sulfo-NHS biotin, thereby preventing subsequent biotinylation of these moieties. Unreacted sulfo-NHS AMCA was inactivated by subsequent incubation with Tris-buffered saline. Cells were then incubated at $37^{\circ} \mathrm{C}$ for an additional 30 min either in normal culture medium or in depolarizing medium supplemented with $\mathrm{KCl}(55 \mathrm{~mm})$ and $2 \mathrm{~mm}$ $\mathrm{Ca}^{2+}$. After washing with cold PBS, cells were incubated for $30 \mathrm{~min}$ at $4^{\circ} \mathrm{C}$ in the presence of $30 \mu \mathrm{g} / \mathrm{ml}$ sulfo-NHS-biotin in PBS at $4^{\circ} \mathrm{C}$ to biotinylate newly inserted proteins, followed by inactivation of unreacted reagent with TBS. Cells were immediately lysed in lysis buffer $(0.1 \%$ Triton X-100, $10 \mathrm{~mm}$ Tris, $150 \mathrm{~mm} \mathrm{NaCl}, 1 \mathrm{~mm} \mathrm{CaCl}_{2}$, and $25 \mathrm{~mm} \mathrm{KCl}$ ) for $30 \mathrm{~min}$, and the cell extracts were obtained by centrifugation in a microcentrifuge $(12,000 \mathrm{rpm}$ for $10 \mathrm{~min})$. Biotinylated receptors were then precipitated by incubating cell extracts with streptavidin beads
(Pierce). Beads were washed with lysis buffer; proteins were eluted from beads in SDS sample buffer; and biotinylated receptors were detected by immunoblotting with HA.11 antibody.

\section{Results}

Selective targeting of recombinant DOR to intracellular membranes in cultured neurons

As a first step toward examining the targeting of recombinant opioid receptors in neurons, we constructed expression constructs encoding FLAG epitope-tagged versions of cloned murine DOR and MOR. When expressed in primary cultured hippocampal pyramidal neurons, MOR was visualized predominantly in a peripheral staining pattern (Fig. $1 A$, bottom panel), consistent with localization in the plasma membrane. In contrast, DOR, although also detectable in the plasma membrane, was most strongly concentrated in intracellular membranes located in the cell body (Fig. $1 A$, top panel). This pattern of DOR localization was observed in the majority $(>75 \%)$ of transfected neurons examined. Furthermore, DOR and MOR were observed to localize differentially when tagged with distinct epitopes (FLAG and $\mathrm{HA}$, respectively) and coexpressed in the same neurons (Fig. $1 B$ ). These results are consistent with the differential localization of endogenously coexpressed DOR and MOR observed in native striatal neurons (Wang and Pickel, 2001) and suggest the existence of an intrinsic difference in the membrane-targeting properties of DOR and MOR, which can be observed by heterologous expression of cloned receptors in cultured neurons.

\section{Receptor-specific targeting of opioid receptors in} neurosecretory PC12 cells

To determine whether differences in the intracellular targeting of DOR and MOR could also be observed in cultured neurosecretory cells, we generated stably transfected PC12 cells expressing epitope-tagged DOR or MOR and selected clones expressing receptors at similar levels $(\sim 0.3 \mathrm{pmol} / \mathrm{mg})$. Both DOR and MOR were localized primarily in the plasma membrane of PC12 cells in the undifferentiated state, similar to the subcellular localization observed in non-neural cells (Keith et al., 1996; Trapaidze et al., 
1996; Murray et al., 1998), with both receptors visualized primarily in the plasma membrane (Fig. $1 C$, left panels). After prolonged NGF treatment of PC12 cells ( $50 \mathrm{ng} / \mathrm{ml} \mathrm{NGF}$ for $5 \mathrm{~d}$ ), which promotes morphological and biochemical differentiation of PC12 cells toward a neuronal phenotype, DOR was visualized both at the cell periphery and in intracellular membrane structures (Fig. 1C, top right panel). In contrast, epitope-tagged MOR, although expressed at similar levels, remained localized primarily in the plasma membrane and was not accumulated in intracellular vesicles under these conditions (Fig. 1C, bottom right panel). This effect was quantified under blinded conditions in multiple experiments (Fig. 1D) and was further confirmed in cells coexpressing DOR and MOR tagged with different epitopes (results not shown).

Because morphological differentiation of PC12 cells involves a complex series of events occurring over a prolonged time course (Reiser and Hamprecht, 1982), we next examined the kinetics of the NGF-induced effect on DOR localization. We were surprised to observe that incubation of cells with NGF for only $60 \mathrm{~min}$, a time point that precedes the majority of morphological and biochemical changes associated with neural differentiation of this cell type, was sufficient to produce a detectable increase in the intracellular membrane pool of DOR (Fig. 2A, top panels). The NGF-induced intracellular pool of DOR was readily detected by fluorescence microscopy, because it was tightly concentrated in a perinuclear distribution, and the internal membrane pool of DOR was clearly resolved from the plasma membrane by confocal optical sectioning through the centers of cells (insets). In contrast, MOR remained localized primarily in the plasma membrane under these conditions, as indicated by both epifluorescence microscopy (Fig. 2A, bottom panels) and confocal optical sectioning (insets), consistent with the failure of even chronic incubation with NGF to detectably alter the subcellular distribution of MOR. This rapid and selective effect of NGF on DOR localization in PC12 cells was confirmed in multiple experiments by blinded analysis of coded specimens (Fig. 2 B). NGF-induced targeting of DOR to intracellular membranes was also observed in transiently transfected PC12 cells, which express DOR at widely different levels, but not in a TrkA-deficient subclone (nnr5) of PC12 cells (Fig. 2C). Furthermore, preincubation of wild-type PC12 cells with the Trk inhibitor K252a inhibited NGF from inducing intracellular membrane localization of DOR (results not shown). Thus receptor-Tyr kinase (RTK) signaling via TrkA is required for NGF-induced intracellular membrane targeting of DOR in these neurosecretory cells.

A possible explanation for why intracellular targeting of DOR is observed selectively in neurosecretory cells could be that this effect is induced only by a subset of RTKs, such as Trk family receptors, which are expressed specifically in certain neurons. Alternatively, it is possible that intracellular targeting of DOR is not a unique consequence of activating a neuron-specific RTK but, instead, reflects a cell type-specific feature of downstream signaling components or of the regulated membrane-trafficking machinery itself. To distinguish between these possibilities, we examined the effect of activating EGF receptors, ubiquitous RTKs expressed in various neural and non-neural cell types. Both NGF and EGF (100 $\mathrm{ng} / \mathrm{ml}$ each) induced a pronounced increase in the intracellular membrane pool of DOR observed $60 \mathrm{~min}$ after addition to serum-starved PC12 cells (Fig. 2D, left panels). However, neither ligand caused detectable intracellular targeting of DOR in HEK293 cells (Fig. 2D, right panels, E, quantification), despite the fact that EGF activates downstream signaling (via MAP kinases) in HEK293 cells to a degree similar to that in PC12
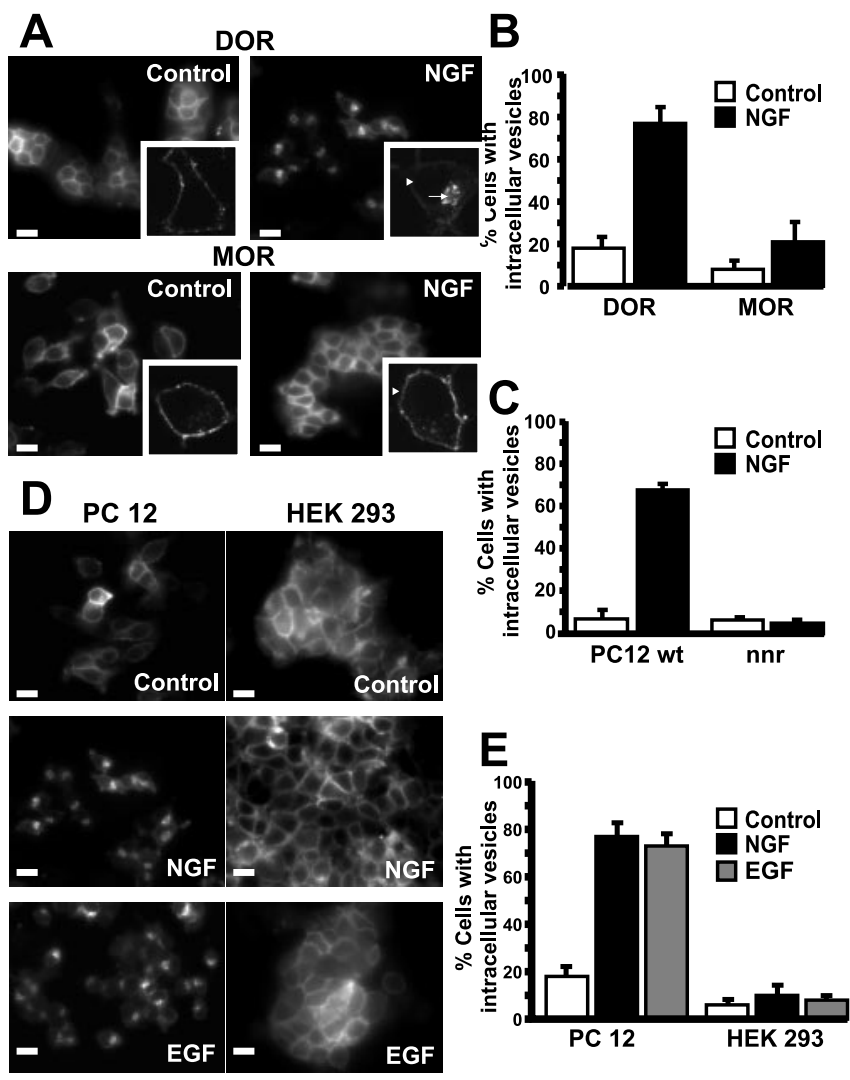

Figure 2. Intracellular targeting of DOR is induced rapidly by receptor-Tyr kinase activation specifically in neurosecretory cells. A, Stably transfected PC12 cells expressing epitope-tagged DOR or MOR were maintained in normal culture medium and then incubated for $60 \mathrm{~min}$ in the absence (Control) or presence (NGF) of $100 \mathrm{ng} / \mathrm{ml}$ added NGF. NGF effects on DOR localization were visualized by epifluorescence microscopy (top row, main panels) and was confirmed at higher magnification in confocal optical sections imaged through the center of cells (bottom right inset; arrow indicates the intracellular membrane pool, and arrowhead indicates plasma membrane). NGF caused no detectable change in the plasma membrane localization of MOR (bottom row, main panels) visualized by epifluorescence (main panels) and in confocal optical sections (bottom right inset; arrowhead indicates plasma membrane). B, Quantification of the acute NGF effect was conducted by scoring $\sim 100$ cells (selected at random in coded specimens) for each condition in each experiment. The proportion of cells characterized by pronounced intracellular localization of DOR or MOR (using the criteria described in Materials and Methods) is presented as mean \pm SEM, compiled from three independent experiments. $C$, Wild-type (PC12 wt) or TrkA-deficient ( $n n r)$ PC12 cells were transiently transfected with HA-tagged DOR and analyzed for NGF-induced intracellular targeting of DOR using same method as that applied to stably transfected cells $(B)$. Data represent means \pm SEM from three independent experiments. D, Localization of HA-tagged DOR in stably transfected PC12 neurosecretory cells or HEK293 cells (selected for comparable levels of DOR expression) was examined in cells maintained in normal culture medium and then serum-starved for $120 \mathrm{~min}$ (Control) and compared with that in serum-deprived cells in which NGF $(100 \mathrm{ng} / \mathrm{ml})$ or epidermal growth factor (EGF; $100 \mathrm{ng} / \mathrm{ml}$ ) was added to the culture medium for $60 \mathrm{~min}$ before fixation. Both NGF and EGF caused pronounced intracellular targeting of DOR in PC12 cells (left pane/s), whereas neither NGF nor EGF caused a detectable effect on DOR localization in HEK293 cells (right panels). E, Quantification of experiments illustrated in $D$. Randomly selected images were scored blindly as in $B$ ( $\sim 100$ cells per condition per experiment). Results are presented as mean fraction of cells displaying pronounced intracellular DOR immunoreactivity \pm SEM, compiled from three independent experiments.

cells (Traverse et al., 1992; Della Rocca et al., 1999). Furthermore, EGF caused no detectable change in the plasma membrane distribution of DOR observed in transfected HeLa or COS cells, non-neural cell types that express relatively large numbers of EGF receptors (data not shown). Thus the cell type specificity of DOR targeting is not a consequence of differences in RTK expression 
but, instead, probably reflects a distinct property of downstream signaling components or of the membrane-trafficking machinery itself present in neurosecretory cells.

\section{DOR is targeted to the intracellular pool from the} biosynthetic pathway

We next examined the membrane pathway mediating the formation of the NGF-induced intracellular membrane pool of DOR. The rapid kinetics with which a detectable intracellular pool was generated suggested initially that this internal pool might result from rapid internalization of receptors. Therefore, we compared the effect of NGF with that of DADLE, an enkephalin analog that induces rapid endocytosis of DOR in neural and non-neural cells (Keith et al., 1996; Trapaidze et al., 1996; Ko et al., 1999; Zhang et al., 1999). DADLE caused a rapid accumulation of intracellular DOR in membrane structures distributed throughout the cytoplasm with a concomitant decrease in plasma membrane immunoreactivity, whereas NGF caused accumulation of DOR in a perinuclear membrane distribution without an obvious loss of receptor immunoreactivity associated with the plasma membrane (Fig. 3A, top panels). To examine specifically the potential role of endocytosis in forming the internal membrane pool, receptors present in the plasma membrane of living cells were labeled with antibody, and subsequent redistribution of antibodylabeled receptors was visualized using fluorescence microscopy. This antibody-feeding experiment revealed that surface-labeled DOR remained in the plasma membrane of cells in the presence of NGF, with no detectable redistribution of labeled receptors into the cytoplasm. In contrast, DADLE caused rapid translocation of surface-labeled DOR to endocytic vesicles located throughout the cytoplasm (Fig. 3A, bottom panels), consistent with previous studies using this method to demonstrate ligandinduced endocytosis of opioid receptors in non-neural cells (Keith et al., 1996) and neurons (Whistler et al., 1999). A biochemical assay of DOR internalization using surface biotinylation followed by cleavage using a membrane-impermeant reducing agent (Cao et al., 1998) confirmed that NGF does not cause detectable internalization of DOR over constitutive levels (observed in the absence of added ligand), in contrast to the pronounced increase of receptor internalization induced by DADLE (Fig. 3B). Finally, NGF did not cause any detectable acute decrease in the number of surface-labeled DOR detected by fluorescence flow cytometry, as indicated by the superimposable surface fluorescence histograms generated from untreated and NGFtreated cells and by the lack of any NGF-induced decrease in mean surface receptor density (Fig. 3C). Thus NGF caused intracellular targeting of DOR by a mechanism distinct from ligandinduced endocytosis of receptors.

To investigate the alternative hypothesis, that the NGFinduced intracellular membrane pool of DOR arises from the biosynthetic rather than the endocytic pathway, we examined the effect of the protein synthesis inhibitor cycloheximide on the formation of the intracellular membrane pool of DOR. Cycloheximide strongly inhibited the NGF-induced accumulation of intracellular DOR (Fig. 3D, compare top left, bottom left panels) without causing any detectable effect on DADLE-induced internalization (Fig. $3 D$, right panels). These observations, confirmed in multiple experiments (Fig. 3E), suggest that NGF causes selective intracellular targeting of recently synthesized DOR from the biosynthetic pathway.
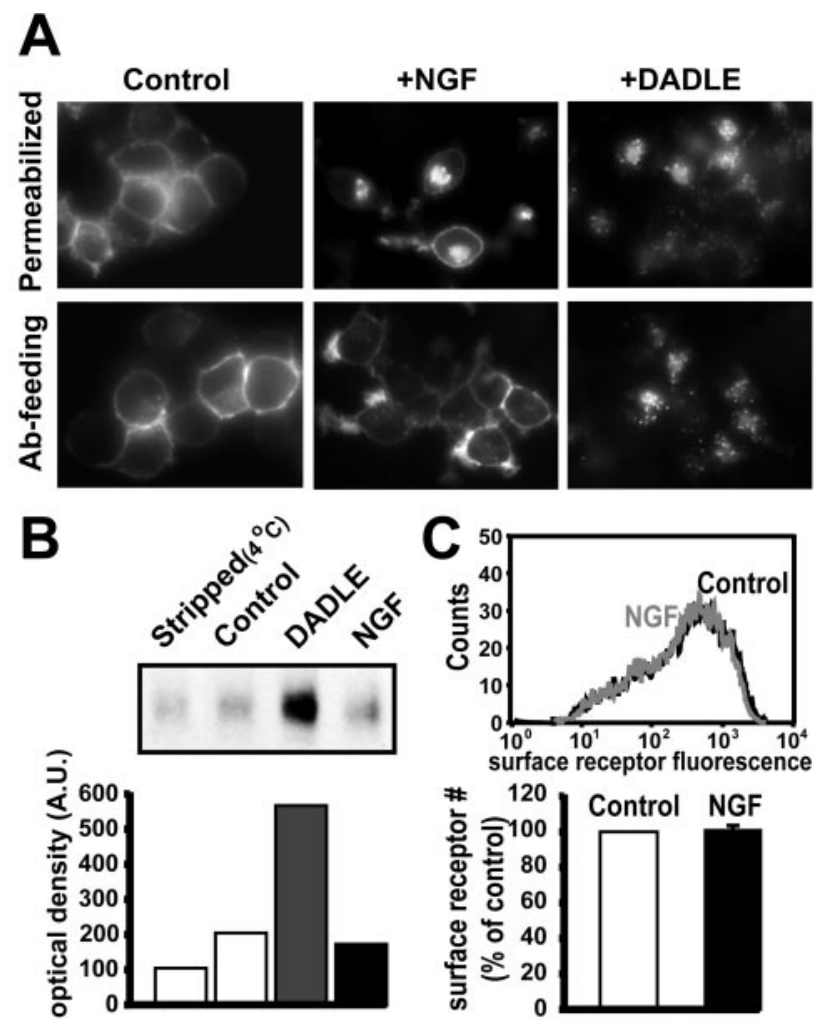

D
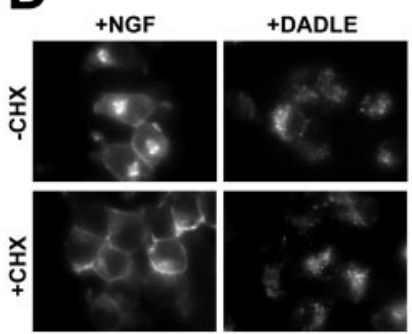

E

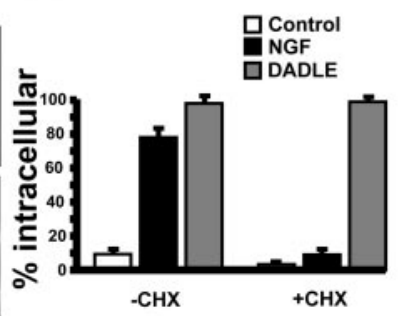

Figure 3. NGF-induced intracellular targeting of DOR is not mediated by endocytosis and requires biosynthesis of new receptor protein. $A$, Stably transfected PC 12 cells expressing HAtagged DOR were treated with $100 \mathrm{ng} / \mathrm{ml} \mathrm{NGF} \mathrm{(1} \mathrm{hr)} \mathrm{or} 10 \mu \mathrm{m}$ of the opioid peptide agonist DADLE (30 min), fixed, and permeabilized to visualize intracellular distribution of DOR by immunofluorescence microscopy (top panels, Permeabilized). To specifically detect endocytosis of receptors, an antibody-feeding experiment was performed (bottom panels, Ab-feeding). Cells were preincubated with anti-HA antibody for 20 min followed by NGF or DADLE treatment as above and then fixed, permeabilized, and processed for immunofluorescence microscopy to detect internalization of surface-labeled receptors. $B$, Endocytosis of DOR expressed in stably transfected PC12 cells was analyzed by surface biotinylation assay, as described in Materials and Methods. Cells were surface-biotinylated at $4^{\circ} \mathrm{C}$ and then incubated with either DADLE (10 $\left.\mu \mathrm{m}\right)$ or NGF ( $100 \mathrm{ng} / \mathrm{ml})$ for 30 and $60 \mathrm{~min}$, respectively, at $37^{\circ} \mathrm{C}$, followed by analysis of detection of internalized receptors by their resistance to cleavage by a membrane-impermeant reducing agent. Stripped indicates the efficiency of cleavage of surface biotins under conditions in which endocytosis is blocked $\left(4^{\circ} \mathrm{C}\right)$, and Control represents the amount of signal representing the low level of (constitutive) internalization observed $\left(\right.$ at $37^{\circ} \mathrm{C}$ ) in the absence of ligand. The top panel is a representative blot, and the bars (bottom panel) represent the results of densitometric scanning from two independent experiments. C, Surface-exposed DOR was analyzed by fluorescence flow cytometry, as described in Materials and Methods. PC12 cells stably expressing DOR were incubated with or without NGF (100 ng/ml) for $1 \mathrm{hr}$, and cell surface receptors were labeled with $\mathrm{HA} 11$ antibody and quantified by flow cytometry. Representative histograms from analysis of 10,000 cells from untreated (Control, black) and NGF-treated specimens (NGF, gray) are overlaid. Nonspecific background staining (determined by staining PC12 cells not expressing epitope-tagged receptors) was $<10 \mathrm{U}$ on this fluorescence scale. D, Stably transfected PC12 cells were incubated with the protein synthesis inhibitor CHX (3 $\mu \mathrm{g} / \mathrm{ml})$ for $30 \mathrm{~min}$ before the treatment with NGF $(100 \mathrm{ng} / \mathrm{ml})$ or DADLE $(10 \mu \mathrm{M})$ followed by immunocytochemical staining to visualize distribution of DOR. E, Quantitative analysis of the results depicted in $D$ was conducted as in Figure 2, and data represent mean \pm SEM from three independent experiments. 


\section{NGF causes retention of recently synthesized DOR in a post-Golgi membrane compartment}

NGF is well known to stimulate biosynthesis of many cellular proteins (Zhou et al., 1995). Thus we used metabolic labeling to examine the effects of NGF specifically on opioid receptor biosynthesis. As expected, NGF caused a significant increase in the amount of radiolabeled DOR protein detected at both 15 and $75 \mathrm{~min}$ after the initiation of metabolic labeling (Fig. 4A, compare lanes 2,3, 4,5). However, NGF caused a similar increase in the biosynthesis of metabolically labeled MOR (Fig. 4A, compare lanes 7,8, 9,10) despite the failure of NGF to induce detectable intracellular targeting of MOR, suggesting that the ability of NGF to induce the accumulation of DOR in cytoplasmic vesicles cannot be explained simply by increased receptor biosynthesis.

We next examined whether NGF affects the transport of newly synthesized opioid receptors through the biosynthetic pathway. Opioid receptors undergo core glycosylation in the endoplasmic reticulum (ER) followed by a series of posttranslational modifications occurring after exit of newly synthesized receptors from the ER. In non-neural cells, ER export is the rate-limiting step in the biosynthetic membrane trafficking of DOR to the cell surface, and, accordingly, the intracellular pool of receptors present in these cells corresponds primarily to immature glycosylated forms (Petaja-Repo et al., 2000). We investigated whether this is true in PC12 cells and, if so, whether NGF creates an intracellular pool of recently synthesized DOR by blocking its export from the ER. At short times after biosynthesis (15 min of labeling), DOR resolved as a major species migrating with an apparent molecular mass of $\sim 39 \mathrm{kDa}$ (Fig. 4A, lanes 2, 3, left arrow), which was detected in receptor-transfected cells but not in control (untransfected) cells (Fig. $4 A$, lane 1 ), confirming the specificity of immunoprecipitation. The molecular mass of this receptor species corresponds to that of the major core glycosylated form of DOR identified previously in the ER of non-neural cells (Petaja-Repo et al., 2000), and this was also indicated by analysis of endoglycosidase $\mathrm{H}$ sensitivity (see below).

Within 75 min after biosynthesis, metabolically labeled DOR resolved as several species with larger apparent molecular masses (Fig. 4A, lanes 4, 5, arrowheads), corresponding to mature glycosylated forms similar to those observed previously in non-neural cells (Tsao and von Zastrow, 2000), which are formed by modification of asparagine-linked glycans occurring after exit of receptors from the ER and delivery to Golgi cisternas (Petaja-Repo et al., 2000, 2001, 2002). Consistent with this, these species were resistant to digestion by endoglycosidase $\mathrm{H}$ but could be degly-

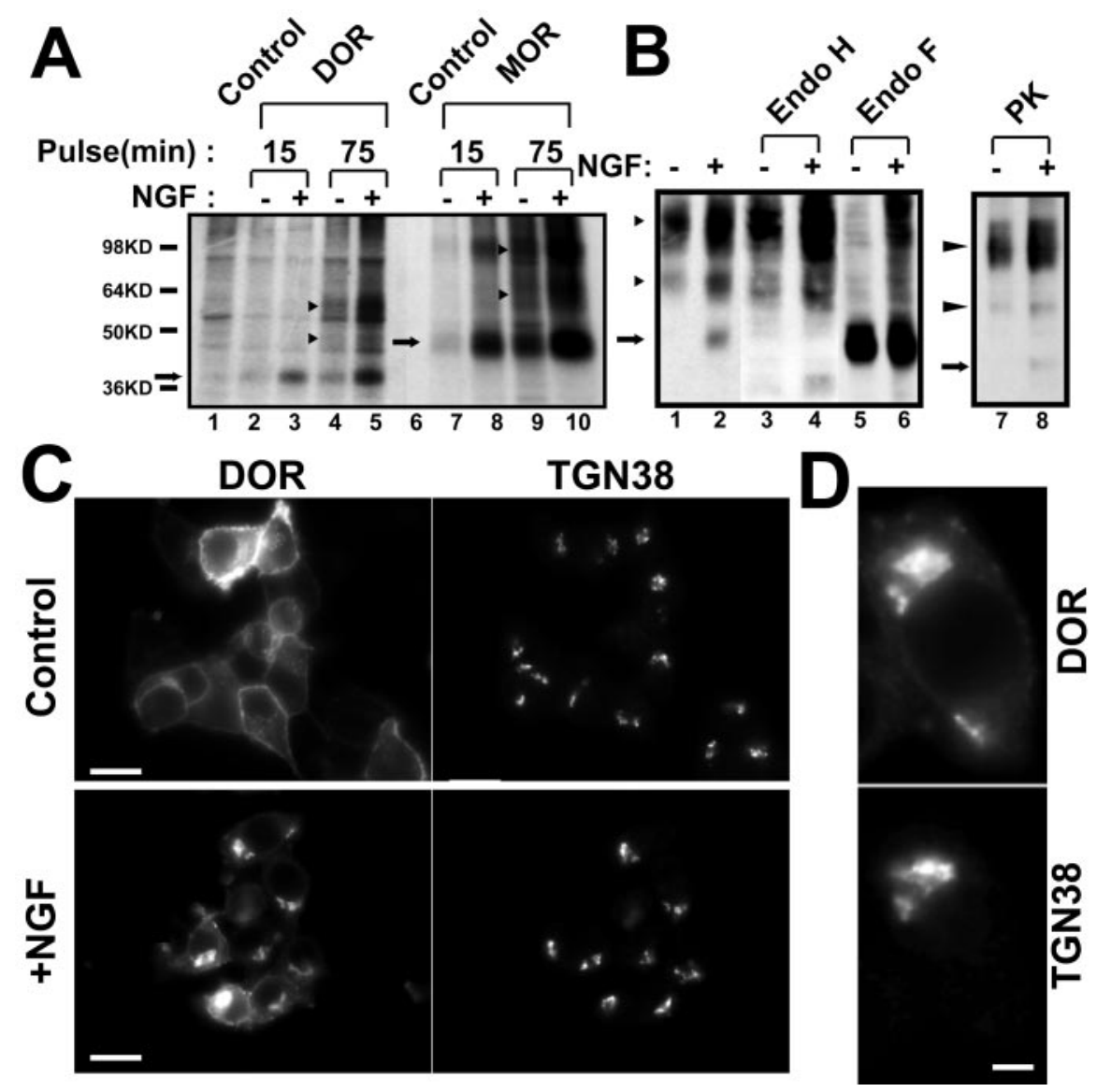

Figure 4. NGF regulates export of DOR from the trans-Golgi network. A, PC12 cells stably expressing HA-tagged DOR or FLAGtagged MOR were preincubated with NGF $(100 \mathrm{ng} / \mathrm{ml})$ for $30 \mathrm{~min}$ and then labeled with $\left[{ }^{35} \mathrm{~S}\right] \mathrm{Cys}$-Met for the indicated times, as described further in Materials and Methods. The cell lysate was immunoprecipitated with antibodies to HA or FLAG epitopes, espectively, and immunoprecipitates were resolved by SDS-PAGE (10\% acrylamide). A fluorograph representative of three indelycosylated) forms of the indicated opioid receptors. NGF increased biosynthesis of both DOR (lanes 3, 5) and MOR (Ianes 8, 10) at to points to a similar extent ( $\sim 80 \%$ as estimated by densitometric scanning). $B$, Enzymatic deglycosylation was used to SDS-PAGE and transferred to nitrocellulose membranes, and receptors were detected using $\mathrm{HA11}$ antibody. To specifically detect the intracellular pool of DOR, intact cells were incubated in the presence of proteinase $\mathrm{K}(P K)$ at $4^{\circ} \mathrm{C}$; to cleave the $\mathrm{N}$-terminal receptors were detected. The predominant form of DOR detected in intracellular membranes of PC12 cells corresponded to the mature, complex glycosylated form. NGF caused a pronounced increase in the amount of this intracellular receptor pool $($ lanes 7,8$)$. Core treated with NGF for $1 \mathrm{hr}$ and then stained for HA-tagged DOR and TGN38, as described in Materials and Methods. Representative epifluorescence microscopic images are shown. Scale bars, $10 \mu \mathrm{m}$. D, Higher magnification of DOR compared with TGN38 distribution in an individual NGF-treated cell. Scale bar, $3 \mu \mathrm{m}$.

cosylated using endoglycosidase F (Fig. 4B, lanes 1-6). Similar results were observed in studies of metabolically labeled MOR. The immature glycosylated form of MOR resolved at $\sim 43 \mathrm{kDa}$ (Fig. 4A, lanes 7, 8, right arrow), and major forms of mature glycoprotein were detected within 75 min after biosynthesis at $\sim 60$ and $\sim 95 \mathrm{kDa}$ (Fig. 4A, lanes 9, 10, arrowheads). Significantly, NGF did not detectably inhibit the biochemical maturation of either opioid receptor. Therefore, NGF did not block export of either DOR or MOR from the ER, despite the NGFinduced increase in biosynthesis of both receptors.

The metabolic-labeling data suggest that the rate-limiting step for DOR biosynthesis in neurosecretory cells is downstream of ER exit, and that NGF may affect a later step of biosynthetic 
membrane trafficking in these cells. If this is true, one would predict that the majority of DOR present at a steady state in intracellular membranes would correspond to biochemically mature, post-ER forms of receptor glycoprotein rather than the core-glycosylated form present in the ER. To test this, we developed a protease protection method, which selectively ablates receptors present in the plasma membrane of intact PC12 cells but leaves the intracellular membrane pool intact. Control experiments using fluorescence flow cytometry indicated that $>95 \%$ of epitope-tagged DORs present in the plasma membrane were proteolyzed under these conditions (results not shown), and intracellular receptors, the only species resistant to proteolysis, were subsequently analyzed by immunoblotting. This method confirmed that NGF caused a pronounced increase in the intracellular pool of DOR in PC12 cells (Fig. 4B, lanes 7, 8). The vast majority of intracellular DOR corresponded to biochemically mature forms, as indicated by electrophoretic mobility (Fig. $4 B$, lane 8 ) and resistance to endoglycosidase $\mathrm{H}$ (Fig. $4 B$, compare lanes 8, 3,4). Even in cells not exposed to NGF, a significant (although much lower) amount of intracellular DOR was detected biochemically, and, again, the major fraction represented mature, post-ER forms of the receptor protein (Fig. 4B, lane 7).

To further investigate the post-ER nature of the NGFsensitive intracellular pool of DOR, we performed colocalization studies using various markers of biosynthetic membranes. The perinuclear distribution of the intracellular pool of DOR induced by NGF differed from the more dispersed distribution of ER membranes visualized in these cells (results not shown). Pronounced overlap was observed with TGN38, an integral membrane protein concentrated specifically in membranes of the trans-Golgi network (Luzio et al., 1990) (Fig. 4C,D). Consistent with this, we also observed close overlap between the intracellular pool of DOR and Golgi matrix 130 (GM130), a Golgi matrix protein that is directly associated with cis-Golgi membranes and is closely adjacent to trans-Golgi elements (Nakamura et al., 1995) but not with transferrin receptors that mark early and recycling endosomes (Hopkins and Trowbridge, 1983; Mukherjee et al., 1997) (results not shown), although DOR colocalizes extensively with transferrin-containing endosomes after endocytosis induced by agonist ligands such as DADLE (Keith et al., 1996). Together these results suggest that the NGF-induced intracellular pool of DOR is localized close to (or contiguous with) Golgi cisternas or the trans-Golgi network, a membrane complex involved in sorting other membrane proteins from the biosynthetic pathway in neurosecretory cells (Wan et al., 1998; Waites et al., 2001). Consistent with this, brefeldin A, which causes redistribution of Golgi and TGN-derived components throughout the cytoplasm in PC12 cells (Waites et al., 2001), produced a pronounced dispersal of intracellular DOR throughout the cytoplasm of NGF-treated cells (results not shown). Together, these results argue strongly that the NGF-induced intracellular pool of DOR observed in PC12 cells does not result from neurotrophin-induced retention of receptors in the ER but, instead, is derived from the biosynthetic pathway after exit of receptors from the ER and delivery to the Golgi apparatus.

\section{NGF regulates the export of previously synthesized DOR from the TGN}

The identification of a post-ER rate-limiting step in the anterograde membrane pathway of DOR suggests two basic hypotheses for the mechanism by which NGF could promote targeting of receptors to a post-Golgi intracellular membrane pool. One possibility is that NGF-induced effects on DOR targeting could arise as a secondary consequence of increased receptor biosynthesis and the existence of a later step of membrane transport, which creates a kinetic "bottleneck" specific for DOR when expression is increased. An alternative possibility is that NGF, in addition to its effects on initial receptor biosynthesis, regulates a distinct step of membrane transport at a late stage of anterograde trafficking, which occurs after receptors are delivered to Golgi or TGN membranes and is specific for DOR. To test these hypotheses, we devised a "pulse-chase" protocol to dissociate effects of NGF on receptor biosynthesis from possible later effects on anterograde membrane trafficking (Fig. 5A). Stably transfected PC12 cells were pulsed by incubation with NGF for $60 \mathrm{~min}$ to induce the formation of a significant intracellular membrane pool of DOR that could be easily visualized by fluorescence microscopy. Then a chase incubation was initiated by adding cycloheximide (CHX) to the culture medium to prevent further biosynthesis and thus to restrict subsequent analysis to the intracellular pool of DOR generated initially in the pulse incubation. The chase incubation was then conducted either in the continued presence of NGF or after NGF washout, and the effect of NGF on the initially formed intracellular receptor pool was subsequently examined (Fig. 5B) in comparison with the intracellular membrane pool present at the beginning of the chase (Fig. $5 B$, panel $a$ ). After washout of NGF and chase incubation in the presence of CHX, the intracellular pool of DOR was completely dissipated within $2 \mathrm{hr}$ (Fig. 5B, panel b). However, the intracellular membrane pool of DOR was stabilized when chase incubations were conducted in the presence of NGF (Fig. 5B, panel d). Significant stabilization of the initially formed intracellular pool of DOR was observed even after $4 \mathrm{hr}$ of chase incubation in the presence of NGF (Fig. 5B, panel e, arrow indicates an example of the residual intracellular DOR visualized in a representative cell). These observations (summarized from blinded analysis in Fig. $5 C$ ) suggest that the NGF-induced accumulation of intracellular DOR is not simply a consequence of increased receptor biosynthesis and that NGF regulates a later (post-ER) event in the anterograde membrane trafficking of DOR, which is required to maintain the internal membrane pool of DOR in the absence of ongoing receptor biosynthesis.

\section{The C-terminal cytoplasmic domain of DOR contains an NGF-regulated intracellular targeting signal}

To begin to examine the mechanism by which NGF selectively promotes intracellular targeting of DOR, we searched for structural determinants that distinguish the intracellular targeting of DOR and MOR in NGF-treated PC12 cells. DOR and MOR share extensive structural homology in their cytoplasmic domains, except for a highly divergent sequence present in a distal portion of the C-terminal cytoplasmic tail. Whereas NGF failed to cause detectable intracellular targeting of wild-type MOR (Figs. 1,2), replacing the divergent 27 residues located in the MOR tail with the corresponding sequence from DOR conferred NGF-induced intracellular targeting of the chimeric mutant opioid receptor (Fig. 6A). This effect was observed reproducibly both after acute (60 min) and chronic (5 d) exposure of cells to NGF (Fig. 6B). The C-terminal cytoplasmic domain has been implicated previously in modulating endocytosis of DOR (Trapaidze et al., 1996), suggesting that this domain contains distinct signals that control both anterograde and endocytic membrane trafficking of opioid receptors.

To determine whether the DOR-derived tail sequence is capable of functioning as an autonomous membrane-targeting signal or whether this specific sequence functions only in the context of 

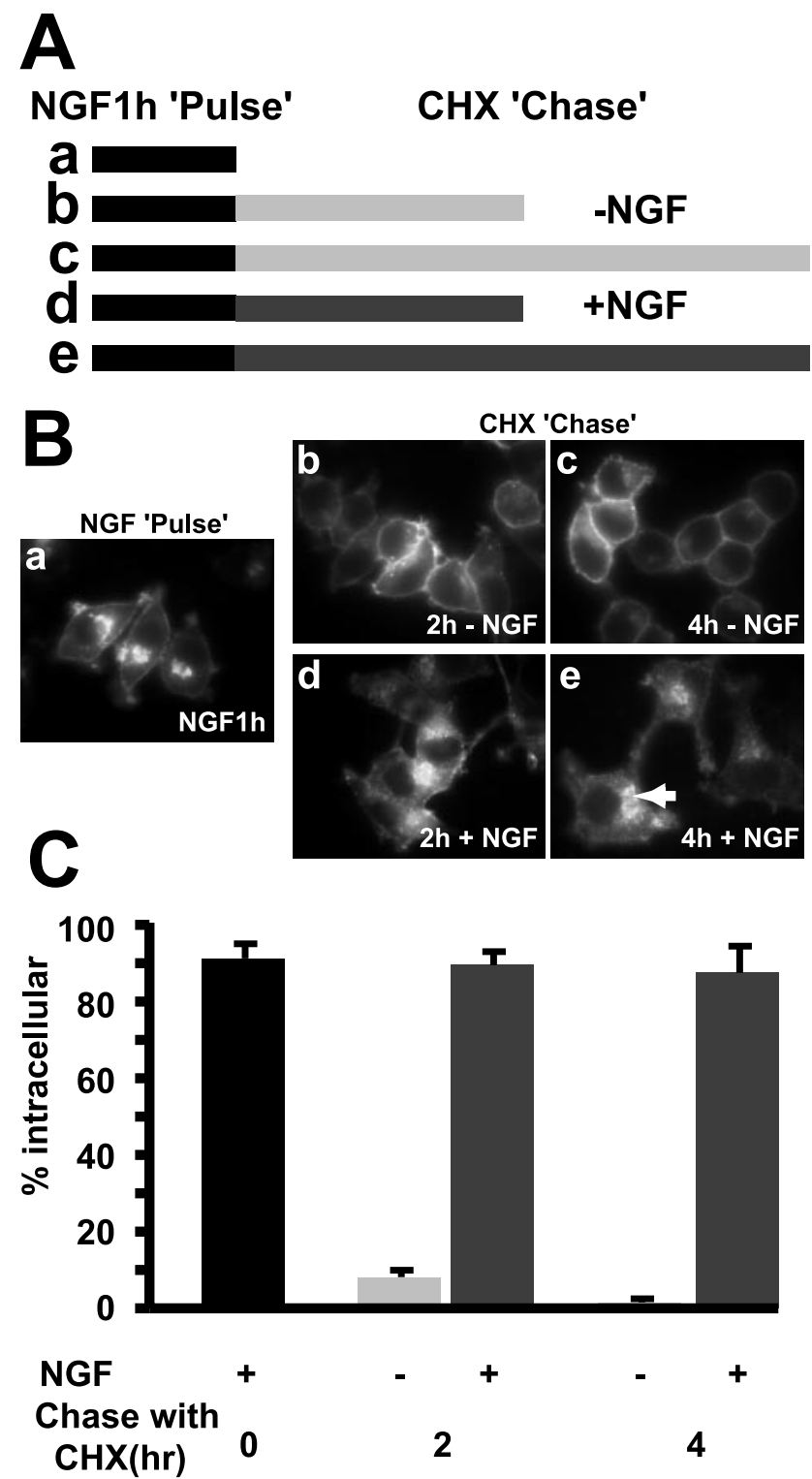

Figure 5. NGF inhibits constitutive trafficking of DOR from the post Golgi membrane pool to the plasma membrane. $A$, Diagram showing a pulse-chase protocol designed to examine the effect of NGF on anterograde membrane trafficking of previously synthesized DOR. Cells were pulsed with NGF (100 ng/ml) for $1 \mathrm{hr}$ to induce the accumulation of receptors in intracellular membranes and chased in the presence of $\mathrm{CHX}(3 \mu \mathrm{g} / \mathrm{ml})$ either with $(d, e)$ or without $(b, c)$ NGF. $B$, Representative micrographs showing effects on the intracellular membrane pool of DOR during the pulse-chase protocol. The internal membrane pool of DOR present initially after the NGF pulse ( $a$ ) was chased out almost completely within $2 \mathrm{hr}$ after removal of NGF $(b)$ and was undetectable after $4 \mathrm{hr}(c)$. The continued presence of NGF in the culture medium markedly stabilized the intracellular pool of DOR, such that a pronounced internal membrane pool was observed after $2 \mathrm{hr}(d)$ and even $4 \mathrm{hr}(e)$ in the absence of new protein synthesis. C, Bar graph displaying the results of quantitative analysis of coded specimens. Data represent means \pm SEM, compiled from three independent experiments.

a full-length opioid receptor, we examined the effect of fusing the DOR-derived tail sequence to CD4, a heterologous type I membrane protein unrelated to GPCRs. In the absence of NGF, both $\mathrm{CD} 4$ and a chimeric mutant version (CD4-DOR) containing the C-terminal cytoplasmic domain derived from DOR were visualized by confocal microscopy predominantly in the plasma membrane (Fig. 6C, left panels). After addition of NGF to the culture medium, CD4 was still localized predominantly in the plasma membrane, whereas the CD4-DOR chimera was observed also in
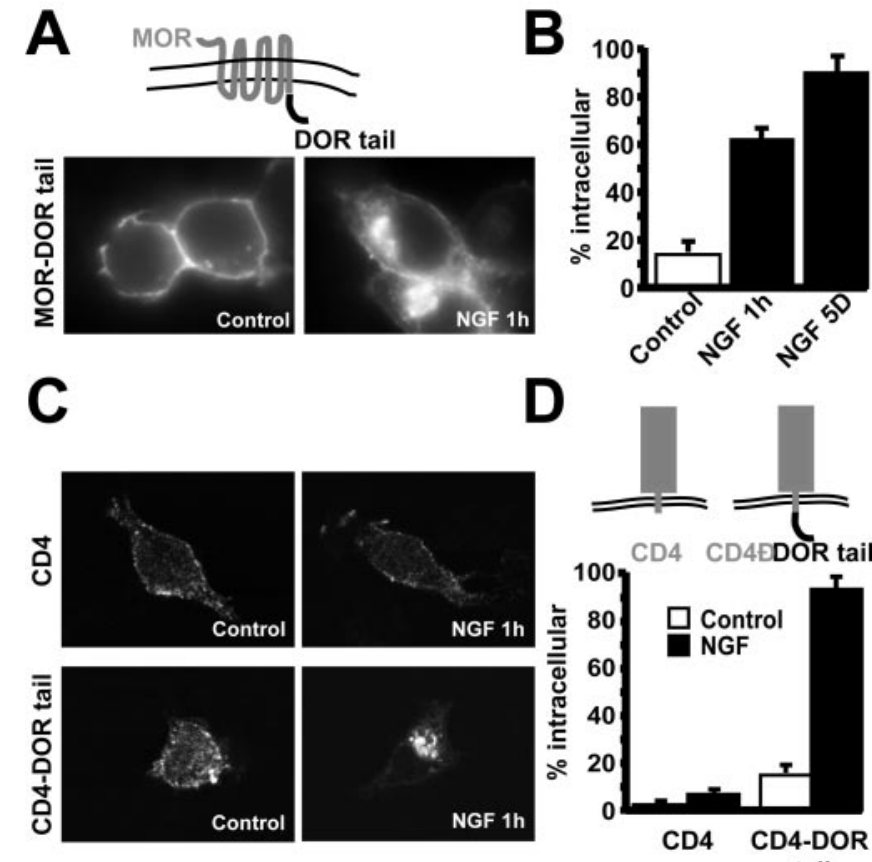

tail

Figure 6. The C-terminal cytoplasmic domain of DOR contains an autonomous intracellular targeting signal. A, Stably transfected PC12 cells expressing a FLAG-tagged chimeric MOR containing divergent residues from the distal cytoplasmic tail of DOR (residues 345-372) were incubated in the absence (Control) or presence (NGF) of NGF (100 ng/ml) for $1 \mathrm{hr}$, fixed, and processed for immunocytochemical staining. Representative micrographs of receptor localization in control and NGF-treated cells are shown. $B$, Quantitative analysis of coded specimens corresponding to the experiment illustrated in $A$, as well as in cells incubated with NGF for $5 \mathrm{~d}$ (as in Fig. 1), was conducted as described above, and data represent means \pm SEM from three independent experiments. C, PC12 cells were transiently transfected with an expression construct encoding CD4 or the CD4-DOR tail fusion, as described in Materials and Methods. Fortyeight hours after transfection, cells were incubated in the absence or presence of $100 \mathrm{ng} / \mathrm{ml} \mathrm{NGF}$ for $1 \mathrm{hr}$, and then cells were fixed, and CD4 proteins were localized using anti-CD4 antibody. Confocal optical sections $(\sim 0.5 \mu \mathrm{m}$ thick) taken through the centers of cells are shown. $D$, Quantitative analysis of the results described in C. Bars represent means \pm SEM from three independent experiments, each involving blinded analysis of $\sim 100$ cells selected at random per condition.

a brightly staining population of intracellular vesicles located in a perinuclear distribution (Fig. $6 C$, right panels, $D$, quantification). These results suggest that the C-terminal cytoplasmic domain of DOR contains an autonomous membrane-trafficking signal, which is sufficient to confer neurotrophin-regulated intracellular targeting on a related GPCR as well as a heterologous integral membrane protein.

Regulated surface insertion of the NGF-induced intracellular pool of opioid receptors

The ability of NGF to regulate export of DOR from the TGN raised the question of the potential physiological function of this regulated membrane-trafficking mechanism. Previous studies of opioid receptor regulation in native neurons suggest that a critical function of intracellular membrane localization is to provide an intracellular pool of receptors that can be delivered to the plasma membrane in response to neuronal depolarization and perhaps other physiological stimuli (Zhang et al., 1998; Shuster et al., 1999; Cahill et al., 2001). Thus we examined whether the neurotrophin-induced intracellular pool of opioid receptors generated in PC12 cells could function in this manner. Stably transfected PC12 cells expressing HA-tagged DOR were incubated in the presence of NGF for 60 min to accumulate a substantial in- 

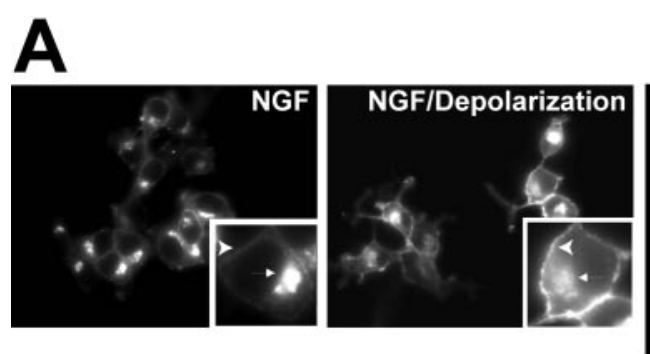

B

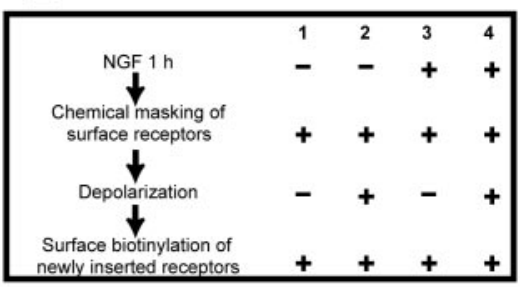

C

Biotinylated (newly inserted)
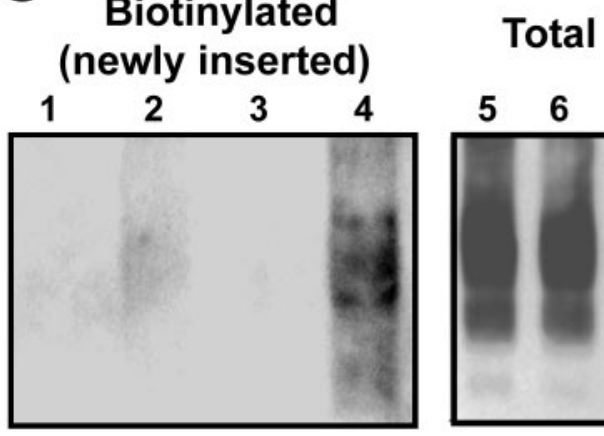

D

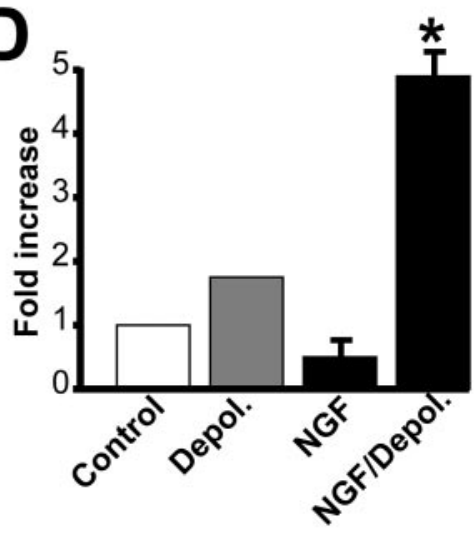

Figure 7. DOR present in the intracellular membrane pool can undergo regulated insertion into the plasma membrane. $A, P C 12$ cells stably expressing HA-tagged DOR were treated with NGF $(100 \mathrm{ng} / \mathrm{ml})$ for $1 \mathrm{hr}$ to induce a visible intracellular membrane pool (left panel, inset, small arrowhead), and then cells were incubated for an additional 30 min in normal medium still containing added NGF (NGF) or the same medium supplemented with $55 \mathrm{~mm} \mathrm{KCI} \mathrm{(NGF/Depolarization)} \mathrm{before} \mathrm{fixation} \mathrm{and} \mathrm{analysis} \mathrm{of} \mathrm{receptor}$ localization by fluorescence microscopy. Inset, Examples of cells suggesting a depolarization-induced decrease of the intracellular membrane pool of DOR (arrow) and a moderate increase in the amount of immunoreactive DOR visualized in the plasma membrane (arrowhead). This effect was seen in the majority ( $\sim 70 \%$ ) of cells but was rarely complete, such that some residual internal DOR staining was visualized in $>90 \%$ cells even after depolarization for $60 \mathrm{~min}$ (results not shown). B, Schematic of the surface modification protocol developed to specifically detect depolarization-induced insertion of DOR into the plasma membrane. Cells were treated with NGF for $1 \mathrm{hr}$ to form intracellular vesicles and incubated with sulfo-NHS AMCA at room temperature to chemically mask receptors present in the plasma membrane by exhaustively derivatizing reactive amine moieties accessible to the cell surface. Cells were then incubated for $30 \mathrm{~min}$ at $37^{\circ} \mathrm{C}$ in the indicated medium and rapidly chilled to $4^{\circ} \mathrm{C}$, and newly inserted receptors were detected by their ability to be labeled using sulfo-NHS-biotin. The numbers above each set of experimental conditions correspond to the lanes in C.C, Extracts were prepared from biotinylated cells, and total cell lysate (Total) or biotinylated proteins isolated from extracts by binding to streptavidin-agarose (Biotinylated) were resolved by SDS-PAGE and analyzed by immunoblotting using anti-HA monoclonal antibody to detect HA-tagged DOR. Biotinylated (newly inserted) receptors detected in PC12 cells incubated control medium in the absence of NGF (lane 1), DOR-expressing cells in control medium followed by depolarization (lane 2), NGF treatment for $60 \mathrm{~min}$ (lane 3), and NGF treatment for $60 \mathrm{~min}$ followed by depolarization (lane 4) are shown. Immunoblotting of total cell lysates (lanes 5, 6, representing 5\% of the total cell lysate) indicated that depolarization caused no detectable change of total DOR present in cells, confirming that the depolarization-induced increase in surface-biotinylated DOR represents a redistribution of intracellular receptors to the cell surface. The immunoblot shown is representative of three independent experiments for NGF-treated cells and two experiments for control cells (not exposed to NGF). D, Quantification of these results by scanning densitometry. Bars represent mean \pm SEM ( $n=3$ independent experiments). *Statistical significance of the difference between depolarized and nondepolarized surface expression, defined as $p<0.02$ using Student's $t$ test.

tracellular membrane pool of receptors. Then cells were depolarized by addition of $55 \mathrm{~mm} \mathrm{KCl}$ to the culture medium, and the effect on internal and plasma membrane pools of DOR was visualized by fluorescence microscopy. Depolarization caused a noticeable decrease in the relative staining intensity of intracellular DOR in the majority of cells $(\sim 70 \%)$ examined (Fig. $7 \mathrm{~A}$, compare left, right panels). Inspection of individual cells at higher magnification (insets) revealed a depolarization-dependent change in the relative amount of DOR present in internal (arrows) and plasma membrane-associated pools (arrowheads), consistent with depolarization-induced translocation to the cell surface.

As an independent and more objective test of this hypothesis, we developed a biochemical assay to specifically detect insertion of receptors into the plasma membrane. HA-tagged DOR present initially in the plasma membrane of stably transfected PC12 cells was chemically masked by reacting intact cells with sulfo-NHS AMCA. This compound is a membrane-impermeant agent that irreversibly modifies surface-accessible amines using the same chemistry as sulfo-NHS biotin, thereby preventing later biotinylation of the preexisting pool of surface receptors. After a subsequent incubation of cells in normal or depolarizing medium, newly inserted receptors were specifically labeled by surface biotinylation using sulfo-NHS biotin (Fig. 7B). No detectable insertion of biotinylatable receptors was observed after subsequent incubation of either control or NGF-pretreated cells for 30 min in normal (nondepolarizing) culture medium (Fig. 7 C, lanes 1, 3, respectively). However, in NGF-pretreated cells incubated under depolarizing conditions after surface receptor masking, a significant signal representing newly biotinylatable receptor protein was detected in the plasma membrane (Fig. 7 C, lane 4). Depolarization increased the surfacebiotinylatable fraction of newly inserted DOR in the plasma membrane (Fig. 7C, lanes 3, 4) without causing a detectable change in the total amount of DOR detected by immunoblotting of whole cell extracts (Fig. 7C, lanes 5, 6), supporting the conclusion that depolarization causes a surface redistribution of the existing pool of intracellular DOR. Quantification of multiple experiments using densitometric scanning (Fig. 7D) confirmed these results and demonstrated that depolarization caused a highly significant $(p<0.02)$ insertion of DOR into the plasma membrane of NGF-pretreated cells. There was also a trend toward a small effect of depolarization on increasing surface delivery of DOR in control (NGF-naive) PC12 cells, consistent with the existence of a small intracellular membrane pool of DOR even under these conditions (Fig. 4), but this effect was small and did not reach statistical significance with the available data. Importantly, the electrophoretic mobility of the newly inserted surface DOR detected in depolarized cells corresponded to that of the mature receptor glycoprotein, consistent with the biochemical properties of the NGF-induced intracellular membrane pool of DOR (Fig. $4 B$ ). Together with the immunocytochemical data (Fig. 7A), these results suggest that a portion of the NGF-induced intracellular membrane pool of DOR can be rapidly mobilized to the cell surface by depolarization-dependent fusion with the plasma membrane.

\section{Discussion}

The present studies suggest that neurosecretory cells and neurons express a specialized mechanism for selectively sorting structurally homologous opioid receptor subtypes to an intracellular membrane pool. In PC12 cells, neurotrophin signaling via the TrkA receptor-Tyr kinase promotes sorting of recently synthesized DOR, after exit from the ER and transport to the Golgi apparatus, to a pool of intracellular membranes located in close proximity to the TGN. Neurotrophin signaling both initiates tar- 
geting of recently synthesized DOR to an intracellular membrane pool and is sufficient to maintain this receptor pool for a prolonged period in the absence of ongoing receptor biosynthesis. The cytoplasmic tail of DOR contains a specific anterograde trafficking signal, which is sufficient to mediate NGF-induced intracellular retention when appended to a distinct opioid receptor or even to a heterologous membrane protein. Furthermore, the neurotrophin-induced intracellular pool of DOR can be mobilized to the plasma membrane by depolarization, suggesting that this trafficking mechanism is relevant to the physiological regulation of opioid receptors in native neurons, where intracellular opioid receptors are thought to function as a "reserve pool" recruited to the plasma membrane in response to neuronal activity (Zhang et al., 1998; Shuster et al., 1999; Cahill et al., 2001).

Although our mechanistic studies were conducted in PC12 neurosecretory cells, a similar intracellular targeting of DOR was observed in transfected hippocampal neurons but not in a variety of non-neural cell types. A potentially important difference between our observations with PC12 neurosecretory cells and transfected pyramidal neurons is that intracellular targeting of DOR in neurons did not require the addition of NGF to the culture medium. This suggests that intracellular targeting of DOR in true neurons may occur constitutively, or that the signaling system regulating this process is activated under normal culture conditions. Indeed, our studies of PC12 cells indicate that TrkA is not the only RTK capable of inducing intracellular targeting of DOR, and the medium required to sustain hippocampal neurons in primary culture contains a number of growth factors distinct from NGF. Thus the present results identify a potentially general role of RTK-mediated signaling in modulating anterograde membrane trafficking of opioid receptors in neuronal cells, and they add to the growing body of evidence indicating that neurotrophins serve multiple functions in neural cell biology distinct from their well established role as growth and survival factors (Schuman, 1999).

The selective regulation of the post-Golgi membrane trafficking of DOR demonstrated in the present study contrasts with previous studies of the trafficking of a variety of integral membrane proteins (including opioid receptors) expressed in nonneural cell types, where anterograde transport is limited by the export of properly assembled proteins from the endoplasmic reticulum and later steps mediating Golgi-to-plasma membrane transport appear to occur by default. Consistent with this, the major fraction of DOR present in cytoplasmic membranes of NGF-treated PC12 cells corresponds to the biochemically "mature" glycoprotein that has already been processed by Golgi enzymes (Fig. 4), in contrast to "immature" forms characteristic of recently synthesized receptors before ER exit (Petaja-Repo et al., 2001). This novel receptor-trafficking mechanism suggests an explanation for the well established observation that, whereas DOR is localized predominantly in the plasma membrane when expressed in non-neural cells, this opioid receptor is selectively localized in intracellular membranes of native neurons (Svingos et al., 1995; Cheng et al., 1997; Zhang et al., 1998).

It will be interesting in future studies to elucidate the specific membrane trafficking machinery that mediates selective intracellular targeting of DOR and to determine how it is regulated by RTK signaling. The ability of ubiquitously expressed EGF receptors to promote intracellular targeting selectively in neurosecretory cells suggests that there may exist cell type-specific substrates of receptor-Tyr kinase signaling that regulate targeting of opioid receptors in neurons. Interestingly, despite the ability of a sequence derived from the $\mathrm{C}$-terminal cytoplasmic domain of DOR to confer NGF-modulated intracellular trafficking both on a mutant opioid receptor (MOR-DOR tail) and on a heterologous integral membrane protein (CD4-DOR tail), this sequence does not contain Tyr residues. Consistent with this, we have not observed NGF-induced phosphorylation of the full-length DOR in PC12 cells (results not shown). Thus we believe that there may exist distinct substrate(s) of neurotrophin-dependent phosphorylation, in addition to opioid receptors themselves, that regulate anterograde membrane trafficking of receptors in neurosecretory cells.

Another important question raised by the present studies is the precise nature of membrane vesicles that mediate regulated surface insertion of opioid receptors. Although endogenously expressed opioid receptors can be observed in dense-core secretory vesicles in CNS neurons, intracellular receptors are also present in other membrane structures that do not resemble either classical dense-core or synaptic vesicles (Svingos et al., 1995; Beczkowska et al., 1997; Zhang et al., 1998; Wang and Pickel, 2001). We have observed that the major fraction of intracellular DOR observed in PC12 cells does not colocalize with secretogranin, a marker of classical dense-core secretory vesicles (results not shown). Furthermore, the sequence of the cytoplasmic tail of DOR does not share detectable homology with anterograde sorting signals that control sorting of membrane proteins into dense core vesicles (Waites et al., 2001). Thus it is possible that opioid neuropeptide receptors are targeted to a distinct population of regulated exocytic vesicles in neurosecretory cells, which are distinct from those mediating regulated secretion of neuropeptides themselves, raising the possibility that there may exist additional pools of exocytic membranes that specifically transport signaling receptors to the plasma membrane of neurons. The idea that there exist multiple pathways of regulated exocytic membrane trafficking in neural cells is consistent with the presence of both classical synaptic vesicles and peptide-containing dense-core secretory vesicles in many neurons, as well as recent evidence for distinct membrane compartments that deliver structural proteins to the presynaptic plasma membrane (Zhai et al., 2001).

Finally, the present observation that neurotrophin signaling both initiates the sorting of biochemically mature DOR to intracellular membranes and is required to maintain the intracellular membrane pool once formed suggests that the post-Golgi membrane trafficking and membrane insertion of signaling receptors in neurons are highly regulated processes. It appears likely that receptor-Tyr kinase signaling regulates post-Golgi membrane trafficking of other neural proteins, in addition to opioid receptors, because the clone of PC12 cells used in our studies do not express detectable levels of endogenous DOR, yet these cells mediate regulated intracellular targeting of this receptor when heterologously expressed. Also, because activation of tumor necrosis factor $\alpha$ receptors has been shown recently to regulate the surface expression of AMPA-type ionotropic glutamate receptors in neurons (Beattie et al., 2002), it is possible that this principle extends to other classes of signaling receptor. Thus we believe that regulated anterograde membrane trafficking is likely to represent a fundamental mechanism of cross talk between distinct receptor signaling systems, by which the biochemical composition, and hence functional activity, of the neuronal plasma membrane is controlled.

\section{References}

Beattie EC, Stellwagen D, Morishita W, Bresnahan JC, Ha BK, Von Zastrow M, Beattie MS, Malenka RC (2002) Control of synaptic strength by glial TNFalpha. Science 295:2282-2285. 
Beczkowska IW, Gracy KN, Pickel VM, Inturrisi CE (1997) Detection of delta opioid receptor and $N$-methyl-D-aspartate receptor-like immunoreactivity in retinoic acid-differentiated neuroblastoma x glioma (NG108-15) cells. J Neurosci Res 47:83-89.

Cahill CM, Morinville A, Lee MC, Vincent JP, Collier B, Beaudet A (2001) Prolonged morphine treatment targets $\delta$ opioid receptors to neuronal plasma membranes and enhances $\delta$-mediated antinociception. J Neurosci 21:7598-7607.

Cao TT, Mays RW, von Zastrow M (1998) Regulated endocytosis of G protein-coupled receptors by a biochemically and functionally distinct subpopulation of clathrin-coated pits. J Biol Chem 273:24592-24602.

Cao TT, Deacon HW, Reczek D, Bretscher A, von Zastrow M (1999) A kinase-regulated PDZ-domain interaction controls endocytic sorting of the beta2-adrenergic receptor. Nature 401:286-290.

Carroll RC, Beattie EC, Xia H, Lüscher X, Altschuler Y, Nicoll RA, Malenka RC, von Zastrow M (1999) Dynamin-dependent endocytosis of ionotropic glutamate receptors. Proc Natl Acad Sci USA 96:14112-14117.

Carroll RC, Beattie EC, von Zastrow M, Malenka RC (2001) Role of AMPA receptor endocytosis in synaptic plasticity. Nat Rev Neurosci 2:315-324.

Cheng PY, Liu-Chen LY, Pickel VM (1997) Dual ultrastructural immunocytochemical labeling of mu and delta opioid receptors in the superficial layers of the rat cervical spinal cord. Brain Res 778:367-380.

Della Rocca GJ, Maudsley S, Daaka Y, Lefkowitz RJ, Luttrell LM (1999) Pleiotropic coupling of $G$ protein-coupled receptors to the mitogenactivated protein kinase cascade: role of focal adhesions and receptortyrosine kinases. J Biol Chem 274:13978-13984.

Evans CJ, Keith DJ, Morrison H, Magendzo K, Edwards RH (1992) Cloning of a delta opioid receptor by functional expression. Science 258:1952-1955.

Gage RM, Kim KA, Cao TT, von Zastrow M (2001) A transplantable sorting signal that is sufficient to mediate rapid recycling of $\mathrm{G}$ protein-coupled receptors. J Biol Chem 276:44712-44720.

He L, Fong J, von Zastrow M, Whistler JL (2002) Regulation of opioid receptor trafficking and morphine tolerance by receptor oligomerization. Cell 108:271-282.

Hopkins CR, Trowbridge IS (1983) Internalization and processing of transferrin and the transferrin receptor in human carcinoma A431 cells. J Cell Biol 97:508-521.

Kaufman DL, Keith Jr DE, Anton B, Tian J, Magendzo K, Newman D, Tran TH, Lee DS, Wen C, Xia Y-R, Lusis AJ, Evans CJ (1995) Characterization of the murine $\mu$ opioid receptor gene. J Biol Chem 270:15877-15883.

Keith DE, Murray SR, Zaki PA, Chu Z, Lissin DV, Kang L, Evans CJ, von Zastrow M (1996) Morphine activates opioid receptors without causing their rapid internalization. J Biol Chem 271:19021-19024.

Keith DE, Anton B, Murray SR, Zaki PA, Chu PC, Lissin DV, Monteillet AG, Stewart PL, Evans CJ, von Zastrow M (1998) mu-Opioid receptor internalization: opiate drugs have differential effects on a conserved endocytic mechanism in vitro and in the mammalian brain. Mol Pharmacol 53:377-384

Ko JL, Arvidsson U, Williams FG, Law PY, Elde R, Loh HH (1999) Visualization of time-dependent redistribution of delta-opioid receptors in neuronal cells during prolonged agonist exposure. Brain Res Mol Brain Res 69:171-185.

Lissin DV, Carroll RC, Nicoll RA, Malenka RC, von Zastrow M (1999) Rapid, activation-induced redistribution of ionotropic glutamate receptors in cultured hippocampal neurons. J Neurosci 19:1263-1272.

Luzio JP, Brake B, Banting G, Howell KE, Braghetta P, Stanley KK (1990) Identification, sequencing and expression of an integral membrane protein of the trans-Golgi network (TGN38). Biochem J 270:97-102.

Man HY, Lin JW, Ju WH, Ju A, Liu L, Becker LE, Sheng M, Wang YT (2000) Regulation of AMPA receptor-mediated synaptic transmission by clathrin-dependent receptor internalization. Neuron 25:649-662.

Mukherjee S, Ghosh RN, Maxfield FR (1997) Endocytosis. Physiol Rev 77:759-803.

Murray SR, Evans CJ, von Zastrow M (1998) Phosphorylation is not required for dynamin-dependent endocytosis of a truncated mutant opioid receptor. J Biol Chem 273:24987-24991.

Nakamura N, Rabouille C, Watson R, Watson N, Hui N, Slusarewicz P, Kreis TE, Warren G (1995) Characterization of a cis-Golgi matrix protein, GM130. J Cell Biol 131:1715-1726.
Petaja-Repo UE, Hogue M, Laperriere A, Walker P, Bouvier M (2000) Export from the endoplasmic reticulum represents the limiting step in the maturation and cell surface expression of the human delta opioid receptor. J Biol Chem 275:13727-13736

Petaja-Repo UE, Hogue M, Laperriere A, Bhalla S, Walker P, Bouvier M (2001) Newly synthesized human delta opioid receptors retained in the endoplasmic reticulum are retrotranslocated to the cytosol, deglycosylated, ubiquitinated, and degraded by the proteasome. J Biol Chem 276:4416-4423.

Petaja-Repo UE, Hogue M, Bhalla S, Laperriere A, Morello JP, Bouvier M (2002) Ligands act as pharmacological chaperones and increase the efficiency of delta opioid receptor maturation. EMBO J 21:1628-1637.

Reiser G, Hamprecht B (1982) Differential effects of various cAMP derivatives on the morphological and electrical maturation of neuroblastoma $\mathrm{x}$ glioma hybrid cells. Exp Cell Res 141:498-503.

Schuman EM (1999) Neurotrophin regulation of synaptic transmission. Curr Opin Neurobiol 9:105-109.

Sheng M, Lee SH (2001) AMPA receptor trafficking and the control of synaptic transmission. Cell 105:825-828.

Shi SH, Hayashi Y, Petralia RS, Zaman SH, Wenthold RJ, Svoboda K, Malinow R (1999) Rapid spine delivery and redistribution of AMPA receptors after synaptic NMDA receptor activation. Science 284:1811-1816.

Shuster SJ, Riedl M, Li X, Vulchanova L, Elde R (1999) Stimulus-dependent translocation of $\kappa$ opioid receptors to the plasma membrane. J Neurosci 19:2658-2664.

Sternini C, Spann M, Anton B, Anton K, Bunnett NW, von Zastrow M, Evans C, Brecha NC (1996) Agonist-selective endocytosis of mu opioid receptor by neurons in vivo. Proc Natl Acad Sci USA 93:9241-9246.

Svingos AL, Cheng PY, Clarke CL, Pickel VM (1995) Ultrastructural localization of delta-opioid receptor and Met5-enkephalin immunoreactivity in rat insular cortex. Brain Res 700:25-39.

Trapaidze N, Keith DE, Cvejic S, Evans CJ, Devi LA (1996) Sequestration of the delta opioid receptor: role of the $\mathrm{C}$ terminus in agonist-mediated internalization. J Biol Chem 271:29279-29285.

Traverse S, Gomez N, Paterson H, Marshall C, Cohen P (1992) Sustained activation of the mitogen-activated protein (MAP) kinase cascade may be required for differentiation of PC12 cells: comparison of the effects of nerve growth factor and epidermal growth factor. Biochem J 288:351-355.

Tsao PI, von Zastrow M (2000) Type-specific sorting of G protein-coupled receptors after endocytosis. J Biol Chem 275:11130-11140.

Tsao PI, von Zastrow M (2001) Diversity and specificity in the regulated endocytic membrane trafficking of G-protein-coupled receptors. Pharmacol Ther 89:139-147.

Waites CL, Mehta A, Tan PK, Thomas G, Edwards RH, Krantz DE (2001) An acidic motif retains vesicular monoamine transporter 2 on large dense core vesicles. J Cell Biol 152:1159-1168.

Wan L, Molloy SS, Thomas L, Liu G, Xiang Y, Rybak SL, Thomas G (1998) PACS-1 defines a novel gene family of cytosolic sorting proteins required for trans-Golgi network localization. Cell 94:205-216.

Wang H, Pickel VM (2001) Preferential cytoplasmic localization of deltaopioid receptors in rat striatal patches: comparison with plasmalemmal $\mu$-opioid receptors. J Neurosci 21:3242-3250.

Whistler JL, Chuang HH, Chu P, Jan LY, von Zastrow M (1999) Functional dissociation of $\mathrm{mu}$ opioid receptor signaling and endocytosis: implications for the biology of opiate tolerance and addiction. Neuron 23:737-746.

Zhai RG, Vardinon-Friedman H, Cases-Langhoff C, Becker B, Gundelfinger ED, Ziv NE, Garner CC (2001) Assembling the presynaptic active zone: a characterization of an active one precursor vesicle. Neuron 29:131-143.

Zhang J, Ferguson SS, Law PY, Barak LS, Caron MG (1999) Agonist-specific regulation of delta-opioid receptor trafficking by $\mathrm{G}$ protein-coupled receptor kinase and beta-arrestin. J Recept Signal Transduct Res 19:301-313.

Zhang X, Bao L, Arvidsson U, Elde R, Hökfelt T (1998) Localization and regulation of the delta-opioid receptor in dorsal root ganglia and spinal cord of the rat and monkey: evidence for association with the membrane of large dense-core vesicles. Neuroscience 82:1225-1242.

Zhou J, Valletta JS, Grimes ML, Mobley WC (1995) Multiple levels for regulation of TrkA in PC12 cells by nerve growth factor. J Neurochem 65 $1146-1156$. 